\title{
Chiral stacking of cyanine or porphyrin as cationic fluorescent dyes in the presence of anionic polysaccharide of hyaluronic acid
}

\author{
Haruko Tobata $^{1}$ (D) Koyuki Nagashima $^{1} \cdot$ Yutaka Okazaki $^{1}$ D $\cdot$ Takashi Sagawa $^{1}$ (D)
}

Received: 7 September 2019 / Accepted: 15 January 2020 / Published online: 22 January 2020

(c) Springer Nature Switzerland AG 2020

\begin{abstract}
Cyanine dye or porphyrin are part of an important family of fluorophores, which have been widely used for photosensitization and optical recording materials. We compared herein the aggregation behaviors of two types of cationic dyes of cyanine or porphyrin in the presence of hyaluronic acid, which contains D-glucuronic acid as anionic helical polysaccharide. UV-Vis absorption and photoluminescence spectra of those aqueous solutions revealed that fluorescent dyes of cyanine form $\mathrm{H}$ - and J-aggregates in the presence of hyaluronic acid. In particular, photoluminescent quenching through the $\mathrm{H}$ - and J-aggregates was observed in the mixture of anionic hyaluronic acid and the cationic cyanine dyes. On the contrary, increment of the intensities of the emission was confirmed in the mixture of porphyrin-hyaluronic acid through the effective interaction between the cationic porphyrin and anionic hyaluronic acid, which was confirmed by remarkable split-Cotton effects of induced circular dichroism in the visible region, though the UV-Vis spectra of porphyrin with hyaluronic acid did not show any sign of aggregation of porphyrin itself. Further addition of hyaluronic acid resulted in the decrease of the extent of the induced circular dichroism, though photoluminescent intensity was kept without quenching. It was also confirmed that the light scattering could be detected only when the remarkable split-Cotton effects were observed. Therefore, cationic porphyrin and anionic hyaluronic acid form complex and the complex might assemble to show the light scattering, though the single molecule of porphyrin was surrounded by polysaccharides and isolated without dye-aggregation.
\end{abstract}

Keywords Fluorescent dye · Polysaccharide $\cdot$ Photoluminescence $\cdot$ Induced chirality

\section{Introduction}

Cyanine dyes are polymethine dyes consist of two nitrogen centers joined by a conjugated chain of odd number of methine carbons or a conjugated system of double bonds [1-3]. Although 3,3'-diethlythiadicarbocyanine iodide (DTDC), one of the cyanine dyes, is an achiral molecule, DTDC formed chiral $\mathrm{H}$-aggregate on duplex DNA [4-9]. Porphyrins are planar macrocyclic molecules containing four pyroles connected in ring fashion through four methine carbons at their a-positions [10]. They are part of an important family of fluorophores, which have been widely used for photosensitization and optical recording materials $[2,3,10]$. Porphyrins are well known to form chiral aggregate in the presence of DNA and act as the stabilizer for the secondary structure of nucleic acid [11-15]. 5, 10, 15, 20-Tetrakis (1-methylpyridinium-4-yl) porphyrin p-toluene sulfonate (TMPyP) is one of the water soluble cationic porphyrins.

Electronic supplementary material The online version of this article (https://doi.org/10.1007/s42452-020-2049-0) contains
supplementary material, which is available to authorized users.

Takashi Sagawa, sagawa.takashi.6n@kyoto-u.ac.jp | ${ }^{1}$ Graduate School of Energy Science, Kyoto University, Yoshida-Honmachi, Sakyo-Ku, Kyoto 606-8501, Japan. 
Hyaluronic acid (HA) is one of interesting helical polysaccharides that has been utilized as a scaffold for dyes through the electrostatic molecular interactions, which resulted in induction of circular dichroism (CD) in the visible region [16-19]. We previously studied utilization of anionic $\mathrm{HA}$ as a scaffold to improve alignment of cationic fluorescent dyes such as 3,3'-diethyl-9-methylthiacarbocyanine (DMTC) [16], DTDC [17], 3,3'-diethylthiacarbocyanine iodide (DTC) [17], 3,3'-diethylthiacyanine iodide (DTTHC) [17], 1-pyrenemethylamine hydrochloride (PyrMA) [18, 19], and TMPyP $[18,19]$. HA binds as the ligand to CD44 that is overexpressed in cancer cells $[20,21]$. Therefore, delivery of anticancer drugs or diagnostic drugs for cancer have been studied by using the specific binding properties of HA [22-24]. In particular near-infrared (NIR) fluorescence imaging agents that specifically accumulate in tumors are needed to those cancer drugs [23-25]. In this context, cyanine dyes and porphyrins derivatives are widely applicable to NIR fluorescence imaging agents [25]. We compared herein the two types of cationic dyes: DTDC or TMPyP, which has different chemical structure, behaviors with HA containing D-glucuronic acid (Scheme 1 ) in aqueous solution in terms of their spectroscopic properties in their UV-Vis absorption and CD spectra in addition to photoluminescence (PL).

\section{Materials and methods}

\subsection{Materials and preparations}

DTDC and TMPyP were purchased from Sigma-Aldrich Corporate. HA powder (HA-Q, extracted from cockscomb. Mw: 530,000-1,330,000 $\mathrm{g} \mathrm{mol}^{-1}$, Japanese Standards of Quasi-Drug Ingredients (JSQI): Sodium Hyaluronate (1), Ingredient Code: 520893) were provided by Kewpie Corporation. HA (or TMPyP) was dissolved in buffer solution $\left[\mathrm{pH}=3.2\right.$ with $\mathrm{HCOOH} / \mathrm{KOH}$, 4.9 with $\mathrm{CH}_{3} \mathrm{COOH} / \mathrm{KOH}, 7.0$ with $\mathrm{Na}_{2} \mathrm{HPO}_{4} / \mathrm{KH}_{2} \mathrm{PO}_{4}$, and 9.0 with $\mathrm{Na}_{2} \mathrm{~B}_{4} \mathrm{O}_{7} / \mathrm{H}_{3} \mathrm{BO}_{3}$ ] or water. DTDC was dissolved in methanol. Those solutions stored at $4{ }^{\circ} \mathrm{C}$ in a refrigerator.

\subsection{UV-Visible, CD, PL spectroscopy and DLS measurement}

UV-Visible absorption spectra were measured using Ultrospec 4000 UV/Visible Spectrophotometer (Pharmacia Biotech) and CD spectra were measured with J-725 CD spectrometer (JASCO, Japan). PL spectra was measured using FP-8600 Spectrophotometer (JASCO, Japan). Dynamic light scattering (DLS) was measured with DLS spectrophotometer (Otsuka Electronics Co., Ltd. DLS-8000DH).
Samples for those measurements were put in a quartz cuvette with $10 \mathrm{~mm}$ optical path length.

\section{Results}

\subsection{UV-Visible and PL spectra of DTDC with HA}

Figure 1 shows UV-Vis absorption and PL spectra of DTDC and $\mathrm{HA}$ in 2.4 vol\% methanol-buffer $(\mathrm{pH}=7.0)$.

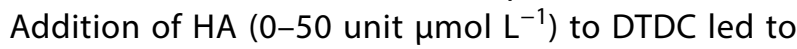
the decrease of the absorbance at $650 \mathrm{~nm}$ and appeared broad absorption band ranging from 500 to $850 \mathrm{~nm}$ (Fig. 1a). The absorption spectra have three absorption peaks at $556 \mathrm{~nm}, 650 \mathrm{~nm}$ and $800 \mathrm{~nm}$. The absorbance at $650 \mathrm{~nm}$ corresponds to the DTDC monomer. While DTDC forms $\mathrm{H}-(556 \mathrm{~nm})$ and J-aggregates $(800 \mathrm{~nm})$ in the presence of HA [17]. Emission peak intensity at $673 \mathrm{~nm}$ of DTDC gradually decreased with increasing [HA] from 2 to 10 unit $\mu \mathrm{mol} \mathrm{L}^{-1}$, while it remained almost constant (viz. saturated) when [HA] was 10 to 50 unit $\mu \mathrm{mol} \mathrm{L}^{-1}$ as shown in Figs. $1 b$ and $2 b$.

\subsection{UV-Visible, PL, CD spectra and DLS of TMPyP with HA}

Figure 3 shows UV-Vis absorption (a), PL (b) spectra of TMPyP and HA in water. Absorption peaks observed at $430,528,562,598$, and $645 \mathrm{~nm}$ are assigned to be TMPyP. Addition of HA, the absorption peak of the Soret band of TMPyP resulted in small $(\sim 3 \mathrm{~nm})$ red shift (Figs. 3a and S1).

Figure 4 shows CD spectra of TMPyP and HA in water.

In the CD spectra, negative split Cotton effect was observed in 390-460 $\mathrm{nm}$, which might be derived from the excitonic interaction of TMPyP molecules themselves (Fig. 4). This negative Cotton effect indicated maximum intensity when $[\mathrm{HA}]$ was 30 unit $\mu \mathrm{mol} \mathrm{L^{-1 }}$ as shown in Fig. 5.

Excess amount of HA reduced the CD intensity. Therefore, most effective interaction between TMPyP and HA was occurred when $[\mathrm{HA}]$ was 30 unit $\mu \mathrm{mol} \mathrm{L}^{-1}$, and further addition of $\mathrm{HA}$ distracted the interaction. This is similar trend observed as the changes of emission peak intensity in the region of $600-900 \mathrm{~nm}$ (Fig. 3b). The intensity at $675 \mathrm{~nm}$ and $720 \mathrm{~nm}$ of TMPyP with HA gradually increased with increasing $[\mathrm{HA}]$ from 5 to 30 unit $\mu \mathrm{mol} \mathrm{L}^{-1}$, though the intensity at $675 \mathrm{~nm}$ reduced remarkably when [HA] was 40 to 100 unit $\mu \mathrm{mol} \mathrm{L}^{-1}$ (Fig. 5b).

Figure 6 indicates UV-Vis absorption (a) and PL (b) spectra of TMPyP and HA in buffer solution.

There are no remarkable changes in the profiles of the absorptions (Fig. 6a). Although CD intensity in the region of $200-250 \mathrm{~nm}$, which is ascribed to the helical structures 
Scheme 1 Chemical structures of DTDC (a), TMPyP (b), and $\mathrm{HA}(\mathbf{c})$

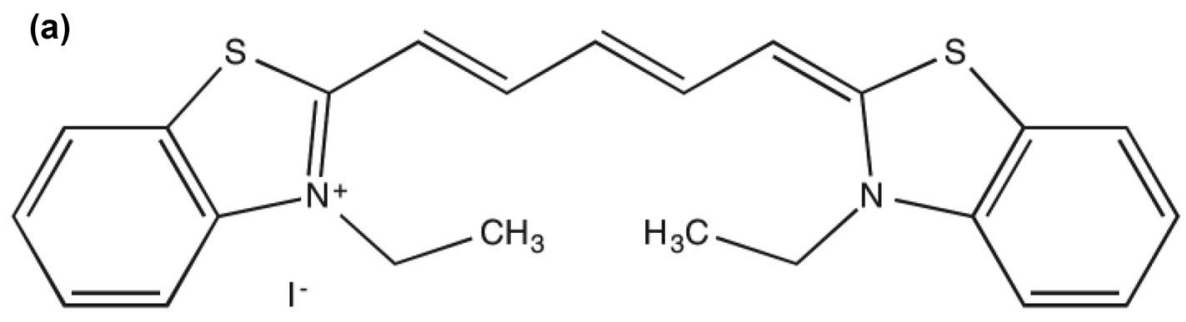

(b)<smiles>CCCc1ccc(S(=O)(=O)c2ccc(C)cc2)cc1</smiles>

(c)

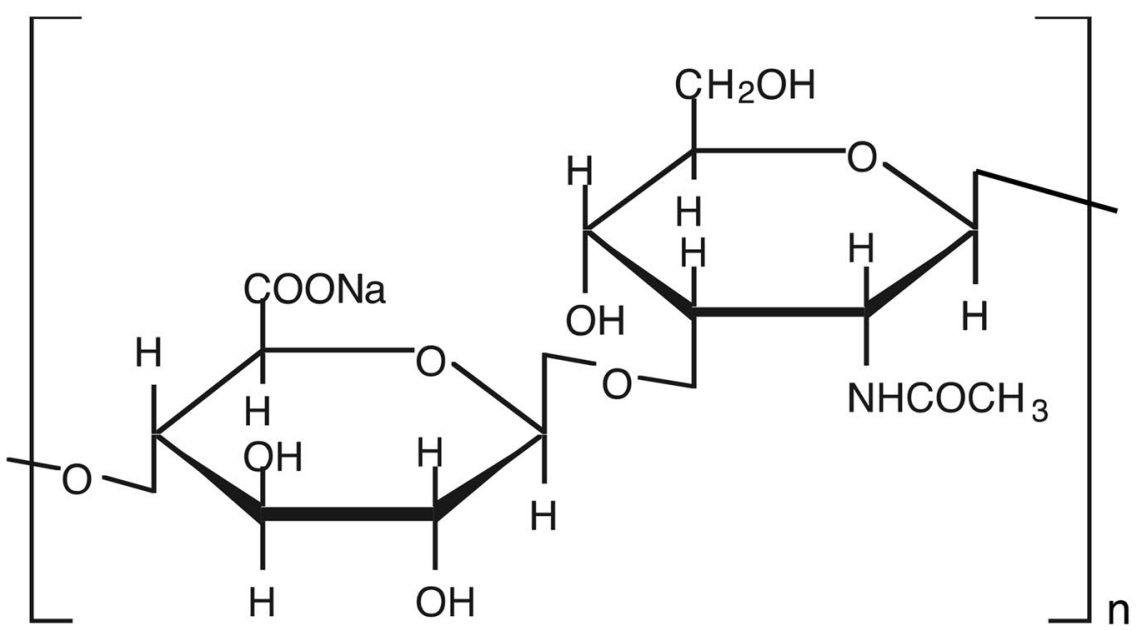

of HA was observed in every sample, there is no CD in the visible region of 390-460 $\mathrm{nm}$ (the data not shown) except when the solvent was water (Fig. 4).

We have measured DLS of TMPyP $\left(10 \mu \mathrm{mol} \mathrm{L}^{-1}\right)$ with $\mathrm{HA}\left(0-100\right.$ unit $\left.\mu \mathrm{mol} \mathrm{L}^{-1}\right)$ in water. The light scattering was detected only when the concentrations of HA were 20,30 , and 40 unit $\mu \mathrm{mol} \mathrm{L}^{-1}$ though the scattering intensities were not so high ranging from 550 to $1027 \mathrm{cps}$ under these conditions. On the other hand, further addition of HA into TMPyP did not show the light scattering. In 

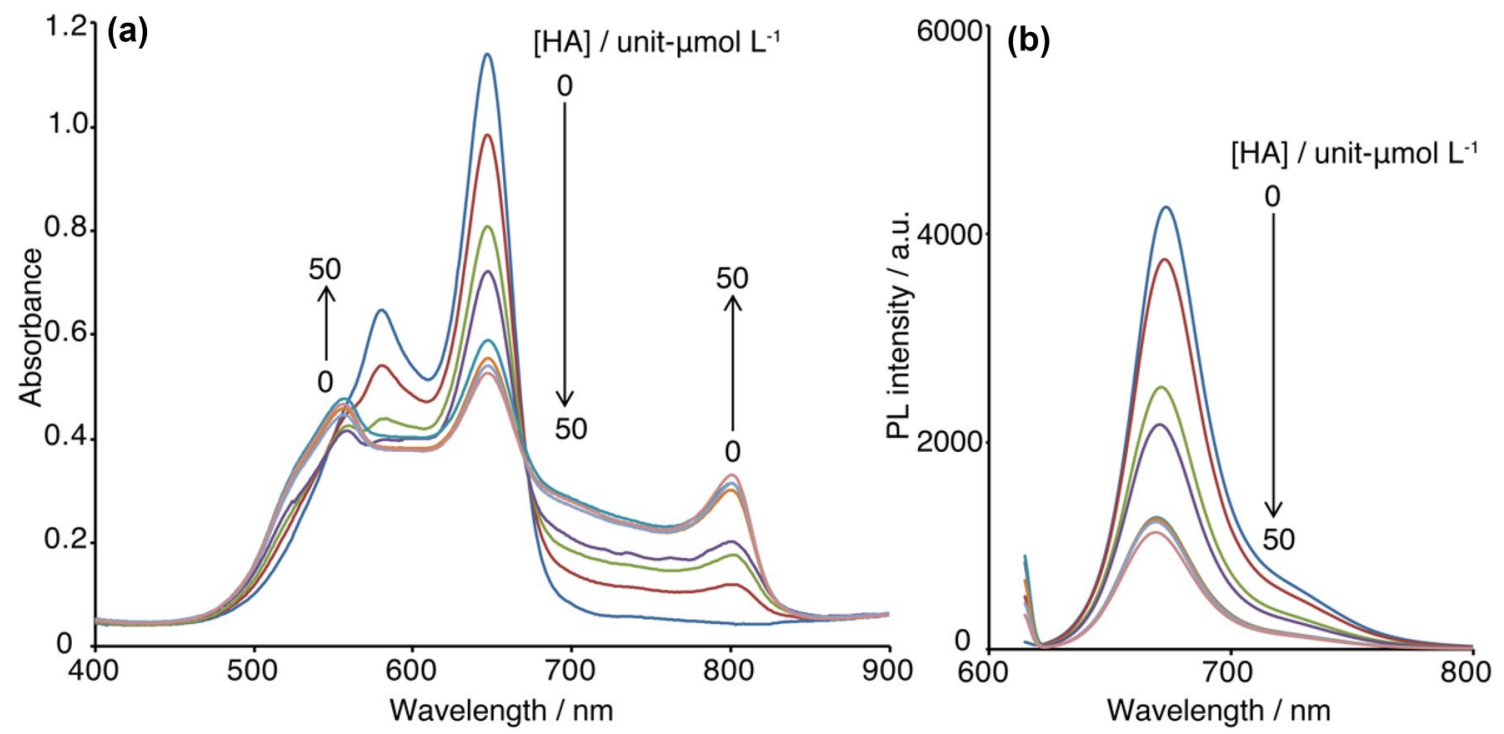

Fig. 1 a UV-Vis absorption and b PL spectra of DTDC $\left(10 \mu \mathrm{mol} \mathrm{L}^{-1}\right)$ and HA $\left(0-50\right.$ unit $\left.\mu \mathrm{mol} \mathrm{L}^{-1}\right)$ in 2.4 vol\% methanol-buffer $(\mathrm{pH}=7.0)$. Excitation wavelength $\left(\lambda_{\mathrm{ex}}\right)$ was $615 \mathrm{~nm}$

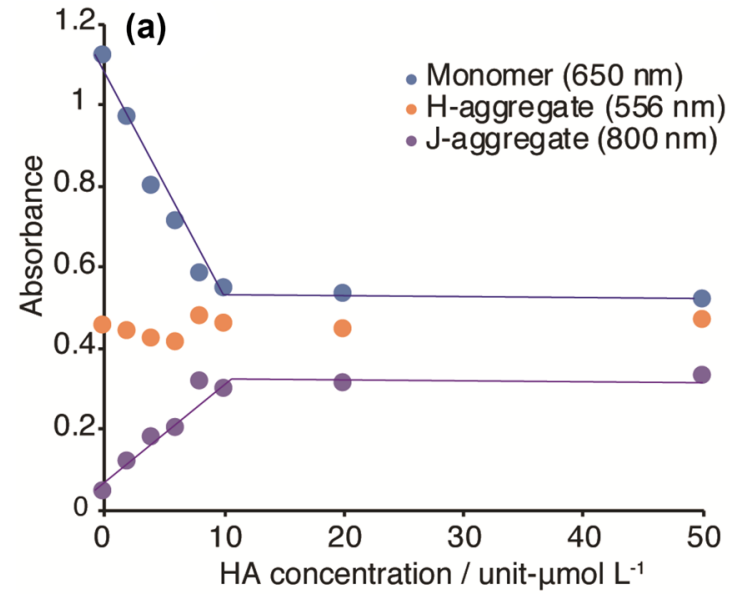

Fig. 2 a Absorbance changes of DTDC $\left(10 \mu \mathrm{mol} \mathrm{L^{-1 } )}\right.$ with $\mathrm{HA}$ $\left(0-50\right.$ unit $\left.\mu \mathrm{mol} \mathrm{L}^{-1}\right)$ at $556 \mathrm{~nm}$ (H-aggregates), $650 \mathrm{~nm}$ (Monomer), $800 \mathrm{~nm}$ (J-aggregates) in 2.4 vol\% methanol-buffer $(\mathrm{pH}=7.0)$.

addition to this, DTDC $\left(10 \mu \mathrm{mol} \mathrm{L}^{-1}\right)$ with HA $(0,10$ and 50 unit $\mu \mathrm{mol} \mathrm{L}^{-1}$ ) did not show any light scattering.

\section{Discussion}

\subsection{UV-Visible spectra and PL spectra of DTDC with $\mathrm{HA}$}

Since $\mathrm{HA}$ one unit $\mu \mathrm{mol} \mathrm{L}^{-1}$ contains one carboxyl group, the ratio of anion of HA to cation of DTDC is 1: 1. In UV-Vis absorption and $\mathrm{PL}$ spectra, when $[\mathrm{HA}]$ is more than 10

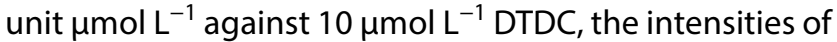

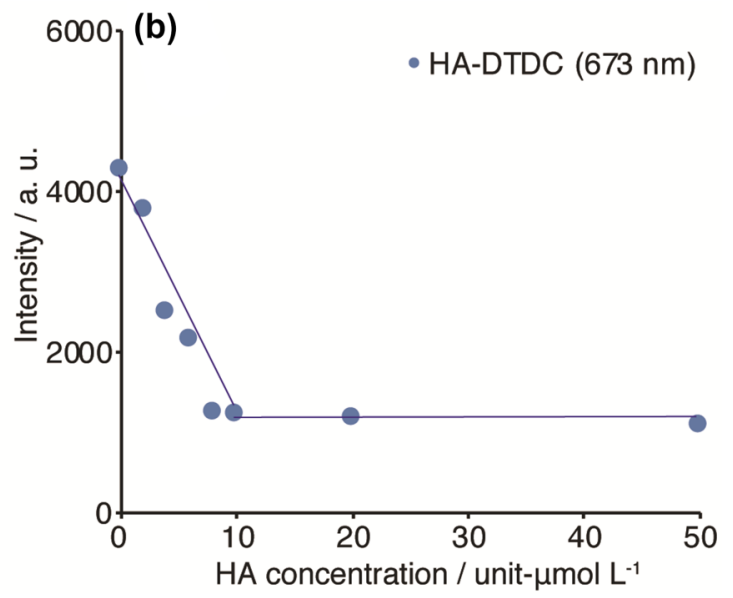

b PL intensity changes of DTDC $\left(10 \mu \mathrm{mol} \mathrm{L}^{-1}\right)$ with HA (0-50

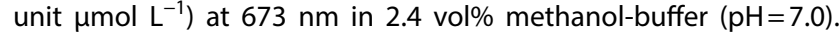
Excitation wavelength $\left(\lambda_{\mathrm{ex}}\right)$ was $615 \mathrm{~nm}$

the UV-Vis absorption spectra and the emission spectra were kept constant (Fig. 2).

Seifert et al. reported that DTDC formed $\mathrm{H}$-aggregates in the presence of DNA, and DTDC with DNA caused only the decrease of the emission peak [4]. PL is often quenched at high concentrations of luminophores known as "aggregation-caused quenching" (ACQ) [26]. ACQ occurs when luminophores contain planar $\pi$-conjugated aromatic rings, which aggregate through strong $\pi-\pi$ stacking interaction [26]. Although DTDC formed $\mathrm{H}$-aggregates with DNA [4], DTDC formed not only $\mathrm{H}$-aggregates but also J-aggregates with HA. Furthermore, decrease of the emission intensity at $673 \mathrm{~nm}$ without the appearance of new bands was 


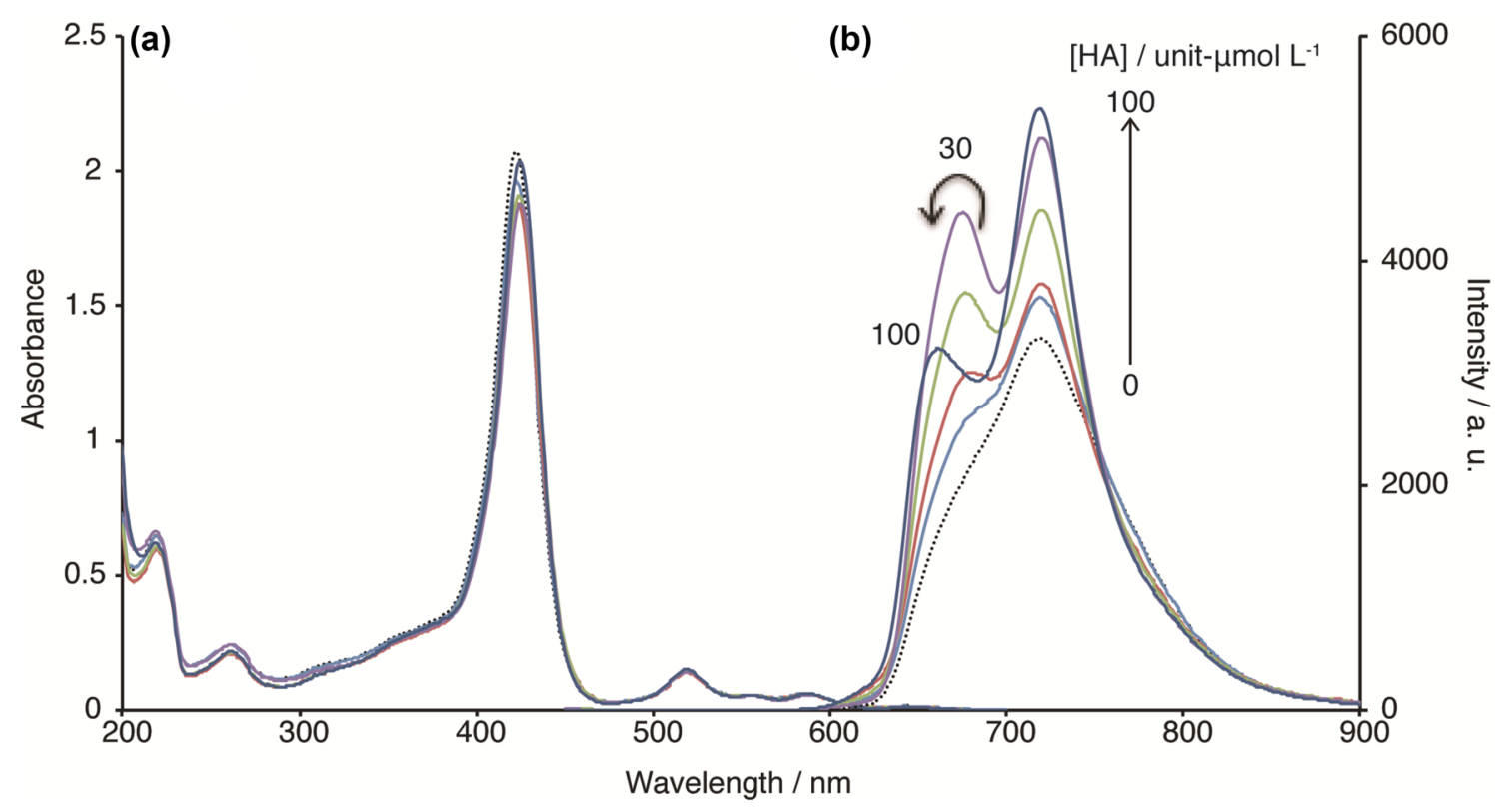

Fig. 3 UV-Vis absorption (a) and PL (b) spectra of TMPyP $\left(10 \mu \mathrm{mol} \mathrm{L}^{-1}\right)$ and HA $\left(0-100\right.$ unit $\left.\mu \mathrm{mol} \mathrm{L}^{-1}\right)$ in water. $\lambda_{\mathrm{ex}}$ was $440 \mathrm{~nm}$

Fig. 4 CD spectra of TMPyP $\left(10 \mu \mathrm{mol} \mathrm{L}^{-1}\right)$ and $\mathrm{HA}(0-100$ unit $\left.\mu \mathrm{mol} \mathrm{L}^{-1}\right)$ in water

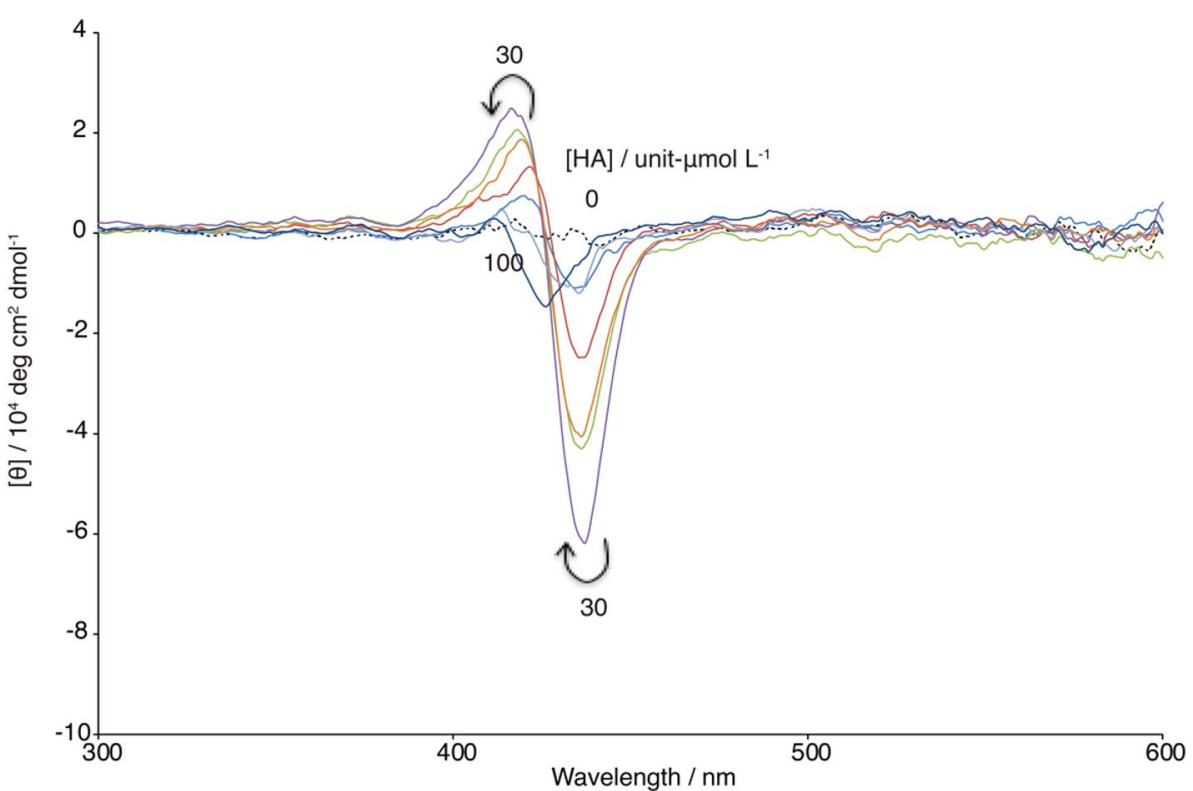

observed. Since the lifetime of the exciton self-trapped (EST) state of the cyanine J-aggregate in aqueous solution is ranged in several hundred of picosecond [27], the fluorescence quenching as mentioned above might be caused by the exciton-exciton annihilation of the J-aggregate of cyanine dye [28]. In addition, the aggregation of DTDC depends on the dispersion ability of the cyanine dye itself in the mixed solution of DTDC and HA and higher PL intensity was obtained when the molecular weight of HA was small (unpublished data). In other words, such quenching of the PL at around $673 \mathrm{~nm}$ was remarkable in the case of larger molecular weight of HA. Therefore, PL-quenching at around $673 \mathrm{~nm}$ observed with increasing the concentration of $\mathrm{HA}$ from 2 to 10 unit $\mu \mathrm{mol} \mathrm{L^{-1 }}$ might be ascribed to $A C Q$, which is caused by the formation of both $\mathrm{H}$ - and J-aggregates of DTDC nearby HA (Fig. 2).

\subsection{UV-Visible, PL, CD spectra and DLS of TMPyP with HA}

Geier and Sasaki reported that porphyrin-helical peptide conjugate has the induced band in the Soret region 

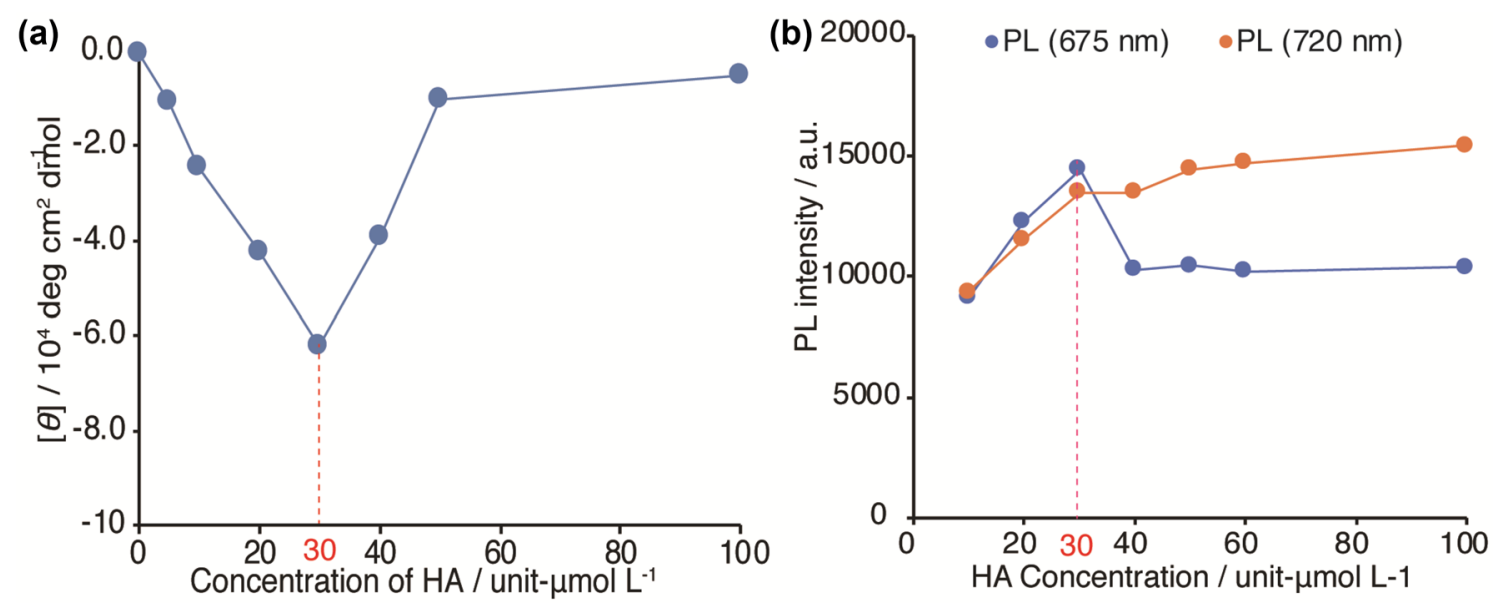

Fig. 5 a Molar ellipticity $[\theta]$ at $437 \mathrm{~nm}$ of TMPyP $\left(10 \mu \mathrm{mol} \mathrm{L} \mathrm{L}^{-1}\right)$ with $\mathrm{HA}\left(0-100\right.$ unit $\left.\mu \mathrm{mol} \mathrm{L}^{-1}\right)$ in water. b PL intensity changes of TMPyP $\left(10 \mu \mathrm{mol} \mathrm{L}^{-1}\right)$ with $\mathrm{HA}\left(0-100\right.$ unit $\left.\mu \mathrm{mol} \mathrm{L}^{-1}\right)$ at $675 \mathrm{~nm}$ and $720 \mathrm{~nm}$ in water. $\lambda_{\mathrm{ex}}$ was $440 \mathrm{~nm}$

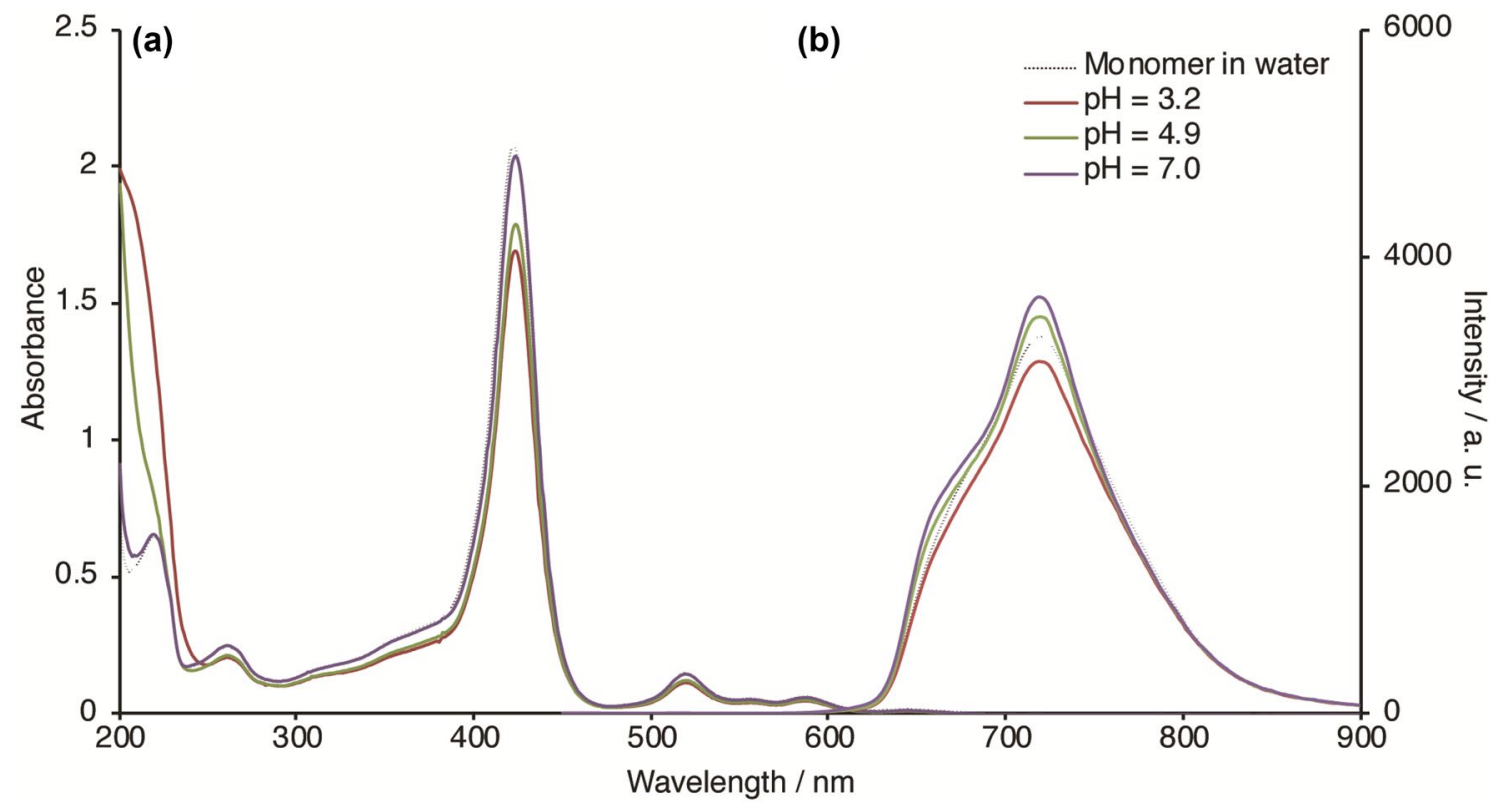

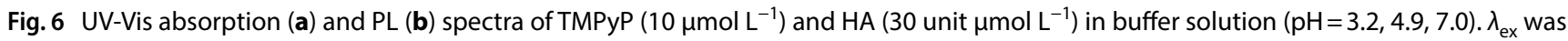
$440 \mathrm{~nm}$

in $10 \mathrm{mM}$ phosphate buffer $(\mathrm{pH}=7)$ [29]. The absorption peak $\left(\lambda_{\max }\right)$ of the Soret band was broadened and shifted by changing the amount of trifluoroethanol (TFE) as follows: $\lambda_{\max }$ at $430 \mathrm{~nm}$ in $10 \% \mathrm{TFE} /$ buffer, $418 \mathrm{~nm}$ in $15 \%$ TFE/buffer, $415 \mathrm{~nm}$ in 20\% TFE/buffer, and $414 \mathrm{~nm}$ in $>30 \%$ TFE/buffer [29]. Therefore, single molecule of porphyrin combined with helical peptide shows induced circular dichroism (ICD) in the Soret region under these conditions. While in the case of the combination of the cationic porphyrin (TMPyP) and the anionic polysaccharide $(\mathrm{HA})$ in this study, although the absorption peaks $\left(\lambda_{\max }\right)$ of the Soret band of TMPyP with or without HA have no remarkable changes ( $3 \mathrm{~nm}), C D$ and PL spectra of TMPyP changed remarkably in the visible region with increment of HA concentration. These results suggest that single molecule of (viz. monomeric) TMPyP might interact with HA. Split emission peaks of $675 \mathrm{~nm}$, which is assigned to be $\mathrm{Q}(0,0)[30]$ and $720 \mathrm{~nm}$ as $\mathrm{Q}(0,1)[30]$ are ascribed to two equilibrium states of inner pyrrole protons of TMPyP tautomers. Since TMPyP has four anions per one molecule, TMPyP has four sites to interact with one unit of HA. Two PL peaks at $675 \mathrm{~nm}$ and $720 \mathrm{~nm}$ increased with increasing the $[\mathrm{HA}]$ from 5 to 30 unit $\mu \mathrm{mol} \mathrm{L^{-1 }}$ as shown in Fig. $5 \mathrm{~b}$. Khurana et al. reported that TMPyP in the presence of 
$\beta$-Cyclodextrin ( $\beta-C D)$ showed similar trend of PL spectral changes [31]. Moreover, the averaged lifetime of the photoexcited singlet state of TMPyP was extended from $5.2 \mathrm{~ns}$ (Free TMPyP) to 11.0 ns (TMPyP- $\beta-C D$ ) [31]. In this context, the increment of those $\mathrm{PL}$ intensities of porphyrin in the presence of $\mathrm{HA}$ is probably ascribed to the enhancement of the hydrophobic atmosphere, which might suppress the non-radiative deactivation. On the other hand, the intensity at $675 \mathrm{~nm}$ decreased by further addition of [HA] more than 40 unit $\mu \mathrm{mol} \mathrm{L}^{-1}$ though another $\mathrm{PL}$ at $720 \mathrm{~nm}$ still increased slightly. Similar trend in the CD spectra of TMPyP and HA in water was observed in the Soret band of 390-460 nm (Figs. 4, 5a) as described above.

We have also measured DLS of TMPyP $\left(10 \mu \mathrm{mol} \mathrm{L}^{-1}\right)$ with $\mathrm{HA}\left(0-100\right.$ unit $\left.\mu \mathrm{mol} \mathrm{L}^{-1}\right)$ in water. It was found that the light scattering could be observed only when the concentrations of HA were 20,30 , and 40 unit $\mu \mathrm{mol} \mathrm{L}^{-1}$ though the scattering intensities were not so high under these conditions. Further addition of HA into TMPyP did not show any light scattering. In this context, even when the UV-Vis spectra of TMPyP with HA do not show any sign of aggregation of porphyrin itself, complex of TMPyP and $\mathrm{HA}$ might form and assemble when [HA] was ranged in 20-40 unit $\mu \mathrm{mol} \mathrm{L}^{-1}$. Therefore, the negative split Cotton effect of TMPyP/HA was observed under these conditions (Fig. 4) and both a decrease of the CD intensities, and a quenching of emission occurs by further adiition of $\mathrm{HA}$, above 1:3 TMPyP/HA molar ratio (blue lines in Fig. 5a, b) were observed.

On the other hand, CD intensity in the region of 200-250 $\mathrm{nm}$ (negative), which is ascribed to the helical structures of $\mathrm{HA}$ gradually increased with increasing the concentration of HA. Similar extent of the CD intensity of HA-TMPyP at $210 \mathrm{~nm}$ was observed to that of HA without TMPyP (Fig. S2).

Furthermore, cationic TMPyP does not interact with anionic HA in buffer electrostatically though it can interact in water. Emission profiles of TMPyP with HA in buffer (Fig. 6) are similar to that of TMPyP itself (viz. without HA as shown in Fig. 4). While fluorescence spectra of TMPyP with HA in water show relatively higher intensities of the emission peak at around $675 \mathrm{~nm}$ (Fig. 5b), which probably corresponds to the effective electrostatic interaction between TMPyP and HA.

\section{Conclusions}

Anionic polysaccharide of $\mathrm{HA}$ incorporated with cationic fluorescent dyes of DTDC or TMPyP has been prepared and investigated the spectroscopic properties. It was found that cyanine dyes form $\mathrm{H}$ - and J-aggregates with HA. PL-quenching at around $673 \mathrm{~nm}$ might correspond to ACQ through predominant formation of the $\mathrm{H}$ - and J-aggregates of DTDC in the presence of HA. On the other hand, TMPyP-HA mixture has chirality with remarkable split-Cotton effects in the visible region and PL intensity at $675 \mathrm{~nm}$ might be reflected by the assembling behavior of TMPyP-HA complexes of cationic TMPyP and anionic HA, though the UV-Vis spectra of TMPyP with HA did not show any sign of aggregation of porphyrin itself. The increment of the PL intensities of porphyrin in the presence of HA is probably ascribed to the enhancement of the hydrophobic atmosphere, which might suppress the non-radiative deactivation. Both a decrease of the CD intensities, and a quenching of emission occurs by further increasing the HA concentration, above 1:3 TMPyP/HA molar ratio were observed. Therefore, through the electrostatic interactions between cationic TMPyP and anionic $\mathrm{HA}$, single molecule of porphyrin was surrounded by polysaccharides and isolated without dye-aggregation. Consequently, although cyanine dye aggregated in the presence of hyaluronic acid and ACQ was observed, single porphyrin interacted with hyaluronic acid electrostatically with induced chirality and discrete fluorophore surrounded by the polysaccharide kept the strong PL intensity.

Acknowledgements We thank Kewpie Corporation for providing the HA powder. We are also grateful to Prof. T. Morii and Assoc. Prof. E. Nakata of Institute of Advanced Energy, Kyoto University for giving an opportunity to use the CD instrument. We also appreciate Mr. S. Kimura of Graduate School of Energy Science, Kyoto University for scientific discussion on DLS measurements.

\section{Compliance with ethical standards}

Conflicts of interest The authors declare that they have no conflict of interest.

\section{References}

1. Brooker LGS, Sprague RH, Smyth CP, Lewis GL (1940) Color and constitution. I. Halochromism of anhydronium bases related to the cyanine dyes. J Am Chem Soc 62:1116-1125

2. Mishra A, Behera RK, Behera PK, Mishra BK, Behera GB (2000) Cyanines during the 1990s: a review. Chem Rev 100:1973-2011

3. Henary M, Paranjpe S, Owens EA (2013) Synthesis and application of benzothia- zole containing cyanine dyes. Heterocycl Commun 19:1-11

4. Seifert JL, Connor RE, Kushon SA, Wang M, Armitage BA (1999) Spontaneous assembly of helical cyanine dye aggregates on DNA nanotemplates. J Am Chem Soc 121:2987-2995

5. Wang MM, Silva GL, Armitage BA (2000) DNA-templated formation of a helical cyanine dye J-aggregate. J Am Chem Soc 122:9977-9986

6. Garoff RA, Litzinger EA, Connor RE, Fishman I, Armitage BA (2002) Helical aggregation of cyanine dyes on DNA templates: effect of dye structure on formation of homo- and heteroaggregates. Langmuir 18:6330-6337 
7. Hannah KC, Armitage BA (2004) DNA-templated assembly of helical cyanine dye aggregates: a supramolecular chain polymerization. Acc Chem Res 37:845-853

8. Hannah KC, Gil RR, Armitage BA (2005) H-1 NMR and optical spectroscopic investigation of the sequence-dependent dimerization of a symmetrical cyanine dye in the DNA minor groove. Biochemistry 44:15924-15929

9. Choi JK, D'Urso A, Trauernicht M, Shabbir-Hussain M, Holmes AE, Balaz M (2011) 3,3'-Diethylthiatricarbocyanine iodide: A highly sensitive chiroptical reporter of DNA helicity and sequence. International Journal of Molecular Sciences 12(11):8052-8062

10. Jiang Y, Sun Z (2019) Self-assembled porphyrin and macrocycle derivatives: from synthesis to function. MRS Bull 44:167-170

11. Chao X, Wang K, Sun L, Cao Q, Ke Z, Cao D, Mao Z (2018) Cationic organochalcogen with monomer/excimer emissions for dualcolor live cell imaging and cell damage diagnosis. ACS Appl Mater Interfaces 10:13264-13273

12. Gibbs EJ, Tinoco PAI, Maestre MF Jr, Ellinas PA, Pasternack RF (1988) Self-assembly of porphyrins on nucleic acid templates. Biochem Biophys Res Commun 157:350-358

13. Hwang YM, Kwon N, Kim SK, Jang YJ (2017) Chiral selective stacking of a cationic porphyrin along Z-form Poly[d(A-T)2]. J Phys Chem B 121:2104-2110

14. Fujiwara N, Mazzola M, Cai E, Wang M, Cave JW (2015) A stabilizer of nucleic acid secondary structure, is a novel acetylcholinesterase inhibitor. PLoS ONE 10(9):e0139167. https://doi. org/10.1371/journal.pone.0139167

15. D'Urso A, Fragalà ME, Purrello R (2013) Non-covalent interactions of porphyrinoids with duplex DNA. In: Paolesse R. (ed) Applications of Porphyrinoids. Topics in Heterocyclic Chemistry, vol 34. Springer, Berlin, Heidelberg, cap. 5, pp 139-174

16. Sagawa T, Tobata $H$, Ihara $H$ (2004) Exciton interactions in cyanine dye-hyaluronic acid (HA) complex: reversible and biphasic molecular switching of chromophores induced by random coil-to-double-helix phase transition of HA. Chem Commun 18:2090-2091

17. Tobata H, Sagawa T (2016) Specific excitonic interactions in the aggregates of hyaluronic acid and cyanine dyes with different length of methine group. Photochem Photobiol Sci 15:329-333

18. Kaerkitcha N, Sagawa T (2018) Amplified polarization properties of electrospun nanofibers containing fluorescent dyes and helical polymer. Photochem Photobiol Sci 17:342-351

19. Kaerkitcha N, Sagawa T (2018) Highly efficient fluorescence resonance energy transfer in electrospun nanofibers containing pyrene and porphyrin. Chem Lett 47:794-796

20. Misra S, Hascall VC, Markwald RR, Ghatak S (2015) Interactions between hyaluronan and its receptors (CD44, RHAMM) regulate the activities of inflammation and cancer. Front Immunol 6:1-31
21. Banerji S, Wright AJ, Noble M, Mahoney DJ, Campbell ID, Day AJ, Jackson DG (2007) Structures of the Cd44-hyaluronan complex provide insight into a fundamental carbohydrateprotein interaction. Nat Struct Mol Biol 14(3):234-239

22. Song Y, Wang Z, Li L, Shi W, Lia X, Ma H (2014) Gold nanoparticles functionalized with cresyl violet and porphyrin via hyaluronic acid for targeted cell imaging and phototherapy. Chem Commun 50:15696

23. Gao S, Wang J, Tian R, Wang G, Zhang L, Li Y, Li L, Ma Q, Zhu $L$ (2017) Construction and evaluation of a targeted hyaluronic acid nanoparticle/photosensitizer complex for cancer photodynamic therapy. ACS Appl Mater Interfaces 9:32509-32519

24. Xu W, Qian J, Hou G, Suo A, Wang Y, Wang J, Sun T, Yang M, Wan $X$, Yao Y (2017) Hyaluronic acid-functionalized gold nanorods with $\mathrm{pH} / \mathrm{NIR}$ dual-responsive drug release for synergetic targeted photothermal chemotherapy of breast cancer. ACS Appl Mater Interfaces 9:36533-36547

25. Luo S, Zhang E, Su Y, Cheng T, Shi C (2011) A review of NIR dyes in cancer targeting and imaging. Biomaterials 32:7127-7138

26. Hong Y, Lam JWY, Tang BZ (2011) Aggregation-induced emission. Chem Soc Rev 40:5361-5388

27. Ma F (2018) Dynamics and coherent control of exciton-exciton annihilation in aqueous J-aggregate. J Phys Chem B 122:10746-10753

28. Khairutdinov RF, Serpone N (1997) Photophysics of cyanine dyes: subnanosecond relaxation dynamics in monomers, dimers, and $\mathrm{H}$ - and J-aggregates in solution. J Phys Chem B 101:2602-2610

29. Geier GR, Sasaki T (1997) The design, synthesis and characterization of a porphyrin-peptid conjugate. Tetrahedron Lett 38(22):3821-3824

30. Uttamlal M, Holmes-Smith AS (2008) The excitation wavelength dependent fluorescence of porphyrins. Chem Phys Lett 454:223-228

31. Khurana R, Kakatkar AS, Chatterjee S (2019) Supramolecular nanorods of (N-Methylpyridyl) porphyrin with captisol: effective photosensitizer for anti-bacterial and anti-tumor activities. Front Chem 7(452):1-11

Publisher's Note Springer Nature remains neutral with regard to jurisdictional claims in published maps and institutional affiliations. 